\title{
DIFFERENTIAL EQUATIONS ON CLOSED SUBSETS OF A BANACH SPACE
}

BY

\section{LAKSHMIKANTHAM, A. RICHARD MITCHELL AND ROGER W. MITCHELL}

ABSTRACT. The problem of existence of solutions to the initial value problem $x^{\prime}=f(t, x), x\left(t_{0}\right)=x_{0} \in F$, where $f \in C\left[\left\{t_{0}, t_{0}+a\right] \times F, E\right], F$ is a locally closed subset of a Banach space $E$ is considered. Nonlinear comparison functions and dissipative type conditions in terms of Lyapunov-like functions are employed. A new comparison theorem is established which helps in surmounting the difficulties that arise in this general setup.

1. Introduction. Recently, in an interesting paper, Martin [4] considers the initial value problem

$$
x^{\prime}=f(t, x), \quad x\left(t_{0}\right)=x_{0},
$$

in a closed subset of a Banach space employing a dissipative type condition in terms of a generalized pairing, namely,

$$
(f(t, x)-f(t, y), x-y)_{+} \leqslant L\|x-y\|^{2} .
$$

The results obtained in [4] crucially depend on the properties of $(x, y)_{+}$and the linearity of the comparison function $g(t, u)=L u$ and are technical. Even to replace the right-hand side of $(1.1)$ by a nonlinear comparison function poses a difficult problem.

In this paper, we extend the existence results in [4], [5] using nonlinear comparison functions and dissipative type conditions in terms of Lyapunov-like functions. A new comparison result (Theorem 2.4) needed to surmount the difficulties is established and employed to prove the general results. The use of Lyapunov-like functions instead of the norm also raises nontrivial problems. For recent results dealing with similar problems see the references in [2], [3], [4] .

2. Preliminary results. Let $E$ be a real Banach space and let $\|\cdot\|$ denote the norm on $E$. Let $F \subset E$ be a locally closed set, that is, for each $x_{0} \in F$, there exists a $b>0$ such that $F_{0}=F \cap B\left(x_{0}, b\right)$ is closed in $E$ where $B\left(x_{0}, b\right)=$ $\left[x \in E:\left\|x-x_{0}\right\| \leqslant b\right]$. Let $R^{+}$denote the nonnegative real line and let

Received by the editors October 22, 1974.

AMS (MOS) subject classifications (1970). Primary 34G05; Secondary 47H15.

Key words and phrases. Banach space, nonlinear differential equation, dissipative ty pe conditions. 
$t_{0} \in R^{+}$. We consider the differential equation

$$
x^{\prime}=f(t, x), \quad x\left(t_{0}\right)=x_{0} \in F .
$$

We list the following assumptions which we use frequently.

(A $\left.\mathrm{A}_{1}\right) f \in C\left[\left[t_{0}, t_{0}+a\right] \times F, E\right]$ and the numbers $a, b>0, M>1$ are chosen such that $\|f(t, x)\| \leqslant M-1$, on $\left[t_{0}, t_{0}+a\right] \times F_{0}$.

$\left(\mathrm{A}_{2}\right) \lim _{h \rightarrow 0} h^{-1} d[x+h f(t, x), F]=0,(t, x) \in\left[t_{0}, t_{0}+a\right] \times F$, where $d(x, F)=\inf [\|x-y\|: y \in F]$.

$\left(\mathrm{A}_{3}\right) g \in C\left[\left[t_{0}, t_{0}+a\right] \times R^{+}, R\right], g(t, 0) \equiv 0$ and $u \equiv 0$ is the unique solution of

$$
u^{\prime}=g(t, u), \quad u\left(t_{0}\right)=0
$$

on $\left[t_{0}, t_{0}+a\right]$.

$\left(\mathrm{A}_{4}\right) V \in C\left[\left[t_{0}, t_{0}+a\right] \times B\left(x_{0}, b\right) \times B\left(x_{0}, b\right), R^{+}\right], V(t, x, x)=0$, $V(t, x, y)>0$ if $x \neq y$,

$$
\left|V\left(t, x_{1}, y_{1}\right)-V\left(t, x_{2}, y_{2}\right)\right| \leqslant L\left[\left\|x-x_{1}\right\|+\left\|y-y_{1}\right\|\right],
$$

if $\left\{x_{n}\right\},\left\{y_{n}\right\}$ are sequences in $B\left(x_{0}, b\right)$ such that $\lim _{n \rightarrow \infty} V\left(t, x_{n}, y_{n}\right)=0$, then $\lim _{n \rightarrow \infty}\left\|x_{n}-y_{n}\right\|=0$ and for $t \in\left[t_{0}, t_{0}+a\right], x, y \in F_{0}$,

$$
\begin{aligned}
& D^{+} V(t, x, y)=\lim _{h \rightarrow 0^{+}} \frac{1}{h}[V(t+h, x+h f(t, x), y+h(t, y))-V(t, x, y)] \\
& \quad \leqslant g(t, V(t, x, y)) .
\end{aligned}
$$

$\left(\mathrm{A}_{5}\right) V \in C\left[B\left(x_{0}, b\right), R^{+}\right], V(0)=0, V(x)>0, x \neq 0$, if $\lim _{n \rightarrow \infty} V\left(x_{n}\right)$ $=0$ with $x_{n} \in B\left(x_{0}, b\right)$, then $\lim _{n \rightarrow \infty}\left\|x_{n}\right\|=0$ and there exists a mapping $M: B\left(x_{0}, b\right) \times E \rightarrow R$ such that:

(a) $M[x, y]$ is upper semicontinuous, i.e., if $\lim _{n \rightarrow \infty}\left(x_{n}, y_{n}\right)=(x, y)$ then $\lim \sup _{n \rightarrow \infty} M\left[x_{n}, y_{n}\right] \leqslant M[x, y]$;

(b) $V(x+y)-V(x) \leqslant M[x, y]+o(\|y\|), x, x+y \in B\left(x_{0}, b\right)$;

(c) $M[x, \lambda y] \leqslant \lambda M[x, y], \lambda \geqslant 0, x \in B\left(x_{0}, b\right), y \in E$;

(d) $M\left[x, y_{1}+y_{2}\right] \leqslant M\left[x, y_{1}\right]+N\|x\|\left\|y_{2}\right\|, N>0, x \in B\left(x_{0}, b\right), y_{1}$, $y_{2} \in E$.

(e) $M[x-y, f(t, x)-f(t, y)] \leqslant g(t, V(x-y)), x, y \in F_{0}, t \in\left[t_{0}, t_{0}+a\right]$.

The construction of a sequence of approximate solutions for (2.1) and the proof that the limit function, when it exists, is a solution of (2.1) is assured by the following results.

LemMA 2.1. Suppose that assumptions $\left(\mathrm{A}_{1}\right)$ and $\left(\mathrm{A}_{2}\right)$ hold. Let $\left\{\epsilon_{n}\right\}$ be a sequence of numbers such that $\epsilon_{n} \in(0,1)$ and $\lim _{n \rightarrow \infty} \epsilon_{n}=0$. Then for each 
positive integer $n$, problem (2.1) has an $\epsilon_{n}$-approximate solution $x_{n}$ from $\left[t_{0}, t_{0}+a\right]$ into $B\left(x_{0}, b\right)$ in the following sense: There exists a nondecreasing sequence $\left\{t_{i}\right\}$ in $\left[t_{0}, t_{0}+a\right]$ such that

(i) $t_{0}^{n}=t_{0}, t_{i}^{n}<t_{i+1}^{n}$ if $t_{i}^{n}<t_{0}+a, t_{i+1}^{n}-t_{i}^{n} \leqslant \epsilon_{n}$ and $\lim t_{i}=t_{0}+a$;

(ii) $x_{n}\left(t_{0}\right)=x_{0}$ and $\left\|x_{n}(t)-x_{n}(s)\right\| \leqslant M|t-s|, t, s \in\left[t_{0}, t_{0}+a\right]$;

(iii) $x_{n}\left(t_{i}^{n}\right) \in F_{0}$ and $x_{n}(t)$ is linear on $\left[t_{i}, t_{i+1}\right]$ for each $i$;

(iv) if $t_{i}^{n}<t_{0}+a$ and $t \in\left(t_{i}^{n}, t_{i+1}^{n}\right)$, then $\left\|x_{n}^{\prime}(t)-f\left(t_{i}^{n}, x_{n}\left(t_{i}^{n}\right)\right)\right\| \leqslant \epsilon_{n}$;

(v) if $(t, y) \in\left[t_{i}^{n}, t_{i+1}^{n}\right] \times F$ with $\left\|y-x_{n}\left(t_{i}^{n}\right)\right\| \leqslant\left(t_{i+1}^{n}-t_{i}^{n}\right) M$, then $\left\|f(t, y)-f\left(t_{i}^{n}, x_{n}\left(t_{i}^{n}\right)\right)\right\| \leqslant \epsilon_{n}$.

LEMMA 2.2. Suppose that the assumptions of Lemma 2.1 hold and that $\lim _{n \rightarrow \infty} x_{n}(t)=x(t)$ for each $t \in\left[t_{0}, t_{0}+a\right]$. Then $x(t)$ is a solution for problem (2.1) on $\left[t_{0}, t_{0}+a\right)$.

For a proof of Lemmas 2.1 and 2.2 see [4].

Lemma 2.3. Let $g \in C\left[R^{+} \times R^{+}, R\right]$ and let the maximal solution $r(t)$ of the scalar differential equation

$$
u^{\prime}=g(t, u), \quad u\left(t_{0}\right)=u_{0} \geqslant 0, \quad t_{0} \in R^{+},
$$

exist on $\left[t_{0}, \infty\right)$. Suppose that $\left[t_{0}, t_{1}\right] \subset R^{+}$. Then there exists an $\epsilon_{0}>0$ such that for $0<\epsilon<\epsilon_{0}$, the maximal solution $r(t, \epsilon)$ of

$$
u^{\prime}=g(t, u)+\epsilon, \quad u\left(t_{0}\right)=u_{0}+\epsilon,
$$

exists on $\left[t_{0}, t_{1}\right]$ and $\lim _{\epsilon \rightarrow \infty} r(t, \epsilon)=r(t)$ uniformly on $\left[t_{0}, t_{1}\right]$.

TheOREM 2.1. Let $g \in C\left[R^{+} \times R^{+}, R\right], m \in C\left[R^{+}, R^{+}\right]$and $\operatorname{Dm}(t) \leqslant$ $g(t, m(t)), t \in\left[t_{0}, \infty\right)-S$, where $S$ is a countable subset of $\left[t_{0}, \infty\right)$ and $D$ is any one of the Dini derivatives. Suppose that the maximal solution $r(t)$ of (2.4) exists on $\left[t_{0}, \infty\right)$ and $m\left(t_{0}\right) \leqslant u_{0}$. Then $m(t) \leqslant r(t), t \geqslant t_{0}$.

For a proof of Lemma 2.3 and Theorem 2.1 see $[1$, pp. 13, 15].

THEOREM 2.2. Let $m(t) \geqslant 0$ be right continuous on $\left[t_{0}, \infty\right)$ with isolated discontinuities at $t_{k}, k=1,2, \ldots, t_{k}>t_{0}$, such that $\left|m\left(t_{k}\right)-m\left(t_{\bar{k}}\right)\right| \leqslant \lambda_{k}$, where $\Sigma_{k=1}^{\infty} \lambda_{k}$ is convergent. Let $g \in C\left[R^{+} \times R^{+}, R\right], g(t, u)$ nondecreasing in $u$ for each $t$, and

$$
\operatorname{Dm}(t) \leqslant g(t, m(t)), \quad t \in\left[t_{k}, t_{k+1}\right], \quad k=0,1,2, \ldots
$$

Then $m\left(t_{0}\right) \leqslant u_{0}$ implies that

$$
m(t) \leqslant r\left(t, t_{0}, u_{0}+\sum_{k=1}^{\infty} \lambda_{k}\right), \quad t \geqslant t_{0},
$$


where $r\left(t, t_{0}, u_{0}\right)$ is the maximal solution of (2.4) existing on $\left[t_{0}, \infty\right)$.

Proof. By Theorem 2.1, we have

$$
m(t) \leqslant r_{0}(t), \quad t \in\left[t_{0}, t_{1}\right),
$$

and $m(t) \leqslant r_{1}(t), t \in\left[t_{1}, t_{2}\right)$, where $r_{0}(t)$ and $r_{1}(t)$ are the maximal solutions of

$$
u^{\prime}=g(t, u) \text {, }
$$

starting at $\left(t_{0}, m\left(t_{0}\right)\right)$ and $\left(t_{1}, m\left(t_{1}\right)\right)$ respectively. Since $m\left(t_{1}\right) \leqslant\left(t_{\overline{1}}\right)+\lambda_{1}$ and $r_{1}^{\prime}(t) \leqslant g\left(t, r_{1}(t)\right)$, by Theorem 2.1, it follows that $m(t) \leqslant r_{11}(t), t \in\left[t_{1}, t_{2}\right)$, where $r_{11}(t)$ is the maximal solution of (2.6) through $\left(t_{1}, m\left(t_{\overline{1}}\right)+\lambda_{1}\right)$. By (2.5), $m\left(t_{\overline{1}}\right) \leqslant r_{0}\left(t_{1}\right)$ and therefore, again applying Theorem 2.1 , we get $m(t) \leqslant r_{12}(t)$, $t \in\left[t_{1}, t_{2}\right)$, where $r_{12}(t)$ is the maximal solution of (2.6) through $\left(t_{1}, r_{0}\left(t_{1}\right)+\lambda_{1}\right)$. Define a function $\rho_{0}(t)$ as follows:

$$
\rho_{0}(t)=\left[\begin{array}{ll}
r_{0}(t)+\lambda_{1}, & t \in\left[t_{0}, t_{1}\right], \\
r_{12}(t), & t \in\left[t_{1}, t_{2}\right) .
\end{array}\right.
$$

Note that $\rho_{0}(t)$ is well defined. Now, by the monotonicity of $g(t, u)$,

$$
\rho_{0}^{\prime}(t)=r_{0}^{\prime}(t)=g\left(t, r_{0}(t)\right) \leqslant g\left(t, r_{0}(t)+\lambda_{1}\right)=g\left(t, \rho_{0}(t)\right), \quad t \in\left[t_{0}, t_{1}\right],
$$

and

$$
\rho_{0}^{\prime}(t)=r_{12}^{\prime}(t)=g\left(t, r_{12}(t)\right)=g\left(t, \rho_{0}(t)\right), \quad t \in\left[t_{1}, t_{2}\right) .
$$

Hence $\rho_{0}^{\prime}(t) \leqslant g\left(t, \rho_{0}(t)\right), t \in\left[t_{0}, t_{2}\right)$, which yields, by Theorem 2.1,

$$
\rho_{0}(t) \leqslant R_{0}(t), \quad t \in\left[t_{0}, t_{2}\right)
$$

where $R_{0}(t)$ is the maximal solution of (2.6) with $R_{0}\left(t_{0}\right)=m\left(t_{0}\right)+\lambda_{1}$. Clearly $m(t) \leqslant \rho_{0}(t) \leqslant R_{0}(t), t \in\left[t_{0}, t_{2}\right)$. Proceeding in the same way and arguing as before, we obtain $m(t) \leqslant R_{1}(t), t \in\left[t_{0}, t_{3}\right)$, where $R_{1}(t)$ is the maximal solution of (2.6) through $\left(t_{0}, m\left(t_{0}\right)+\lambda_{1}+\lambda_{2}\right)$. It therefore follows, repeating the arguments successively,

$$
m(t) \leqslant r\left(t, t_{0}, m\left(t_{0}\right)+\sum_{k=1}^{\infty} \lambda_{k}\right), \quad t \geqslant t_{0},
$$

where $r\left(t, t_{0}, u_{0}\right)$ is the maximal solution of (2.4) and the proof is complete.

To prove an existence result in a general case, it becomes necessary to construct an appropriate sequence of right continuous functions with isolated discontinuities and then employ Theorem 2.2. The next lemma serves this purpose but employs $\left(A_{5}\right)$ since $\left(A_{4}\right)$ is not strong enough. 
LEMMA 2.4. Let $m, n$ be positive integers and let the sequence $\left\{t_{k}\right\}$ be the minimal refinement of the sequences $\left\{t_{i}^{n}\right\},\left\{t_{j}^{m}\right\}$. Assume that $\left(\mathrm{A}_{1}\right),\left(\mathrm{A}_{2}\right)$, $\left(A_{3}\right)$, and $\left(A_{5}\right)$ hold. Then there exists a sequence of functions $\left\{y_{p}\right\}$ from $\left[t_{0}, t_{0}+a\right]$ into $B\left(x_{0}, b\right)$ satisfying the following properties:

(i) $\left\|y_{p}(t)-x_{0}\right\| \leqslant M\left(t-t_{0}\right)$ and $\left\|y_{p}(t)-y_{p}(s)\right\| \leqslant M|t-s|, t, s \in$ $\left[t_{k}, t_{k+1}\right], m \leqslant p \leqslant n$

(ii) $y_{p}\left(t_{k^{\prime}+1}\right) \in F_{0}, p=m, n$;

(iii) for all but a countable number of $t \in\left[t_{k}, t_{k+1}\right), y_{p}^{\prime}(t)$ exists such that

$$
\begin{aligned}
M\left[y_{n}(t)\right. & \left.-y_{m}(t), y_{n}^{\prime}(t)-y_{m}^{\prime}(t)\right] \\
& \leqslant g\left(t, V\left(y_{n}(t)-y_{m}(t)\right)\right)+\left(1+N\left\|y_{n}(t)-y_{m}(t)\right\|\right)\left(\epsilon_{n}+\epsilon_{m}\right) ;
\end{aligned}
$$

(iv) if $t_{i}^{n}, t_{j}^{m} \leqslant t_{k} \leqslant t_{k+1} \leqslant t_{i+1}^{n}, t_{j+1}^{m}$, then

$$
\begin{array}{ll}
y_{n}\left(t_{k+1}\right)=x_{n}\left(t_{k+1}\right) & \text { if } t_{k+1}=t_{i+1}^{n}, \\
y_{n}\left(t_{k+1}\right)=y_{n}\left(t_{\bar{k}+1}\right) & \text { if } t_{k+1}<t_{i+1}^{n},
\end{array}
$$

and $\left\|y_{n}(t)-x_{n}(t)\right\| \leqslant 3\left(t-t_{i}^{n}\right) \epsilon_{n}, t \in\left[t_{k}, t_{k+1}\right)$;

$$
\begin{array}{ll}
y_{m}\left(t_{k+1}\right)=x_{m}\left(t_{k+1}\right) & \text { if } t_{k+1}=t_{j+1}^{m}, \\
y_{m}\left(t_{k+1}\right)=y_{m}\left(t_{\bar{k}+1}\right) & \text { if } t_{k+1}<t_{j+1}^{m},
\end{array}
$$

and $\left\|y_{m}(t)-x_{m}(t)\right\| \leqslant 3\left(t-t_{j}^{m}\right) \epsilon_{m}, t \in\left[t_{k}, t_{k+1}\right)$;

(v) $\left\|y_{p}\left(t_{i+1}^{p}\right)-y_{p}\left(t_{i+1}^{p}\right)\right\| \leqslant 3\left(t_{i+1}^{p}-t_{i}^{p}\right) \epsilon_{p}, p=m, n$, i being an integer.

This lemma is an extension of Lemma 1 in [4] and consequently we only indicate changes in the proof.

PROOF. Let $k$ be a nonnegative integer and suppose that $y_{p}(t), p=n, m$, is defined on $\left[t_{0}, t_{k}\right]$ satisfying the properties on $\left[t_{0}, t_{k}\right]$. To show that $y_{p}(t)$ can be suitably extended to $\left[t_{0}, t_{k+1}\right]$, we define inductively the sequence $\left\{s_{q}\right\}$ and $y_{p}(t)$ on $\left[t_{k}, s_{q+1}\right]$ as follows: if $s_{q}=t_{k+1}$, then $s_{q+1}=t_{k+1}$ and if $s_{q}<t_{k+1}$, we let $s_{q+1}=s_{q}+\gamma_{q}$ where $\gamma_{q} \geqslant 0$ is such that

$$
\text { (3) } \begin{aligned}
M\left[\left(y_{n}\left(s_{q}\right)+x\right)-\left(y_{m}\left(s_{q}\right)+y\right), f\left(s_{q}, y_{n}\left(s_{q}\right)\right)-f\left(s_{q}, y_{m}\left(s_{q}\right)\right)\right] \\
\leqslant g\left(s_{q}+\sigma, V\left(y_{n}\left(s_{q}\right)+x-y_{m}\left(s_{q}\right)-y\right)\right)+\epsilon_{n}+\epsilon_{m},
\end{aligned}
$$

whenever $\|x\|,\|y\| \leqslant \gamma_{q} M$ and $0<\sigma \leqslant \gamma_{a}$.

$$
s_{q}+\gamma_{q} \leqslant t_{k+1}
$$

(4. $\quad \gamma_{q}$ is the largest number satisfying (1) to (3).

The condition $\left(\mathrm{A}_{2}\right)$, (a) and (e) of $\left(\mathrm{A}_{5}\right)$ imply that $\gamma_{q}>0$. Using (2), for $p=m$, $n$, let $y_{p}\left(s_{q+1}\right) \in F$ such that

$$
\left\|y_{p}\left(s_{q}\right)+\left(s_{q+1}-s_{q}\right) f\left(s_{q}, y_{p}\left(s_{q}\right)\right)-y_{p}\left(s_{q+1}\right)\right\| \leqslant\left(s_{q+1}-s_{q}\right) \epsilon_{p},
$$


and for $t \in\left(s_{q}, s_{q+1}\right)$ define

$$
y_{p}(t)=\left[\left(t-s_{q}\right) y_{p}\left(s_{q+1}\right)+\left(s_{q+1}-t\right) y_{p}\left(s_{q}\right)\right]\left(s_{q+1}-s_{q}\right)^{-1} \text {. }
$$

It is easy to see that $y_{p}\left(s_{q+1}\right) \in F_{0},\left\|y_{p}(t)-y_{p}(s)\right\| \leqslant M|t-s|$, and $\left\|y_{p}(t)-x_{0}\right\| \leqslant M\left(t-t_{0}\right), t, s \in\left[t_{k}, s_{q+1}\right]$. Thus (1) holds for $t \in\left[t_{k}, s_{q+1}\right)$. Moreover, by (2.7) and (2.8), it follows that

$$
\left\|y_{p}^{\prime}(t)-f\left(s_{q}, y_{p}\left(s_{q}\right)\right)\right\| \leqslant \epsilon_{p}, \quad t \in\left(s_{q}, s_{q+1}\right) .
$$

Since $\left\|y_{p}(t)-y_{p}\left(s_{q}\right)\right\| \leqslant \gamma_{q} M$ and $\left|t-s_{q}\right| \leqslant \gamma_{q}$, we get from (2.9), (3) and (d) of $\left(A_{5}\right)$,

$$
\begin{aligned}
M\left[y_{n}(t)-\right. & \left.y_{n}(t), y_{n}^{\prime}(t)-y_{m}^{\prime}(t)\right] \\
\leqslant & M\left[y_{n}(t)-y_{m}(t), f\left(s_{q}, y_{n}\left(s_{q}\right)\right)-f\left(s_{q}, y_{m}\left(s_{q}\right)\right)\right] \\
& +N\left\|y_{n}(t)-y_{m}(t)\right\|\left(\epsilon_{n}+\epsilon_{m}\right) \\
& \leqslant g\left(t, V\left(y_{n}(t)-y_{m}(t)\right)\right)+\left(1+N\left\|y_{n}(t)-y_{m}(t)\right\|\right)\left(\epsilon_{n}+\epsilon_{m}\right),
\end{aligned}
$$

for $t \in\left(s_{q}, s_{q+1}\right)$. Hence (iii) is true for $t \in\left[t_{k}, s_{q+1}\right)$. The rest of the proof is very much the same as the proof of Lemma 1 in [4] with appropriate changes. In particular $(x, y)_{+}$has to be replaced by $M[x, y]$. We therefore omit the remaining details.

Finally we need the following result which relates $M\left[x(t), x^{\prime}(t)\right]$ to $D_{+} V(x(t))$ for any differentiable function $x(t)$. This is required relative to condition $\left(\mathbf{A}_{5}\right)$.

Lemma 2.5. Assume $\left(\mathrm{A}_{5}\right)$. Let $x(t)$ be any differentiable function on $\left[t_{0}, t_{0}+a\right]$ into $B\left(x_{0}, b\right)$. Then

$$
D_{+} V(x(t)) \leqslant M\left[x(t), x^{\prime}(t)\right], \quad t \in\left[t_{0}, t_{0}+a\right] .
$$

For a proof of this lemma and use of assumptions like $\left(A_{5}\right)$ see $[6$, pp. 142, 144].

3. Main existence results. We begin with a simple but illustrative existence result which is in the spirit of Wazewski [5].

TheOREM 3.1. Assume that conditions $\left(\mathrm{A}_{1}\right),\left(\mathrm{A}_{2}\right)$ and $\left(\mathrm{A}_{3}\right)$ hold. Suppose further that for $t \in\left[t_{0}, t_{0}+a\right], x, y \in F_{0}$,

$$
\|f(t, x)-f(t, y)\| \leqslant g(t,\|x-y\|),
$$

and $g(t, u)$ is nondecreasing in $u$ for each $t$. Then problem (2.1) has a unique solution on $\left[t_{0}, t_{0}+a\right]$.

Proof. Let $n, m$ be positive integers and let $m(t)=\left\|x_{n}(t)-x_{m}(t)\right\|$, $t \in\left[t_{0}, t_{0}+a\right]$. If $t \in\left(t_{i}^{n}, t_{i+1}^{n}\right) \cap\left(t_{j}^{m}, t_{j+1}^{m}\right)$, then 


$$
\begin{aligned}
D^{+} m(t) \leqslant & \left\|x_{n}^{\prime}(t)-x_{m}^{\prime}(t)\right\| \\
\leqslant & \left\|f\left(t, x_{n}\left(t_{i}^{n}\right)\right)-f\left(t, x_{m}\left(t_{j}^{m}\right)\right)\right\|+\left\|f\left(t, x_{n}\left(t_{i}^{n}\right)\right)-f\left(t_{i}^{n}, x_{n}\left(t_{i}^{n}\right)\right)\right\| \\
& +\left\|f\left(t, x_{m}\left(t_{j}^{m}\right)\right)-f\left(t_{j}^{m}, x_{m}\left(t_{j}^{m}\right)\right)\right\|+\left\|x_{n}^{\prime}(t)-f\left(t_{i}^{n}, x_{n}\left(t_{i}^{n}\right)\right)\right\| \\
& +\left\|x_{m}^{\prime}(t)-f\left(t_{j}^{m}, x_{m}\left(t_{j}^{m}\right)\right)\right\| .
\end{aligned}
$$

By (iv) of Lemma 2.1 and (3.1), we get

$$
D^{+} m(t) \leqslant g\left(t,\left\|x_{n}\left(t_{i}^{n}\right)-x_{m}\left(t_{j}^{m}\right)\right\|\right)+2\left(\epsilon_{n}+\epsilon_{m}\right) .
$$

Now using (i) and (ii) of Lemma 2.1, we see that

$$
\begin{aligned}
\left\|x_{n}\left(t_{i}^{n}\right)-x_{m}\left(t_{j}^{m}\right)\right\| \leqslant & \left\|x_{n}\left(t_{i}^{n}\right)-x_{n}(t)\right\|+\left\|x_{n}(t)-x_{m}(t)\right\| \\
& +\left\|x_{m}\left(t_{j}^{m}\right)-x_{m}(t)\right\| \\
& \leqslant M\left(\epsilon_{n}+\epsilon_{m}\right)+\left\|x_{n}(t)-x_{m}(t)\right\| .
\end{aligned}
$$

Inequality (3.2) yields, in view of the monotony of $g(t, u)$ in $u$ and (3.3),

$$
D^{+} m(t) \leqslant g\left(t, m(t)+\beta_{m, n}\right)+\eta_{m, n},
$$

where $\beta_{m, n}=M\left(\epsilon_{n}+\epsilon_{m}\right)$ and $\eta_{m, n}=2\left(\epsilon_{n}+\epsilon_{m}\right)$. Setting $v(t)=m(t)+\beta_{m, n}$, we have $D^{+} v(t) \leqslant g(t, v(t))+\eta_{m, n}$. This inequality holds for all but a countable number of $t \in\left[t_{0}, t_{0}+a\right]$. Also, $v\left(t_{0}\right)=\beta_{m, n}$. Hence by Theorem 2.1, we have

$$
m(t) \leqslant v(t) \leqslant r_{m, n}(t), \quad t \in\left[t_{0}, t_{0}+a\right],
$$

where $r_{m, n}(t)$ is the maximal solution of $u^{\prime}=g(t, u), u\left(t_{0}\right)=\beta_{m, n}$. Since $\beta_{m, n}, \eta_{m, n} \rightarrow 0$ as $n, m \rightarrow \infty$, we see, by Lemma 2.3 , that $\lim _{n, m \rightarrow \infty} r_{m, n}(t)$ $=r(t)$ uniformly on $\left[t_{0}, t_{0}+a\right]$, where $r(t)$ is the maximal solution of (2.2). By $\left(\mathrm{A}_{3}\right)$ it follows that $m(t) \equiv 0$ on $\left[t_{0}, t_{0}+a\right]$, as $n, m \rightarrow \infty$. Thus the sequence $\left\{x_{n}(t)\right\}$ is uniformly Cauchy on $\left[t_{0}, t_{0}+a\right]$ and the existence of a solution for problem (2.1) follows by Lemma 2.2. The proof of uniqueness of solutions is standard. Hence the proof is complete.

The improvement of (3.1) even to

$$
\limsup _{h \rightarrow 0^{+}} \frac{1}{h}[\|x-y+[f(t, x)-f(t, y)]\|-\|x-y\|] \leqslant g(t,\|x-y\|),
$$

for $x, y \in F_{0}$ and $t \in\left[t_{0}, t_{0}+a\right]$, creates several difficulties that demand additional assumptions. In view of this, we wish to utilize better candidates than $\|x-y\|$. Consequently, the results that follow employ Lyapunov-like functions and the theory of differential inequalities in a variety of ways.

THEOREM 3.2. Suppose that assumptions $\left(\mathrm{A}_{1}\right)$ to $\left(\mathrm{A}_{4}\right)$ hold. Then the convexity of $F_{0}$ implies that problem $(2.1)$ has a unique solution on $\left[t_{0}, t_{0}+a\right]$. 
Proof. The convexity of $F_{0}$ implies by (iii) of Lemma 2.1 that $x_{n}(t) \in F_{0}$ for all $t \in\left[t_{0}, t_{0}+a\right]$. Let $m, n$ be positive integers and let

$$
m(t)=V\left(t, x_{n}(t), x_{m}(t)\right), t \in\left[t_{0}, t_{0}+a\right] .
$$

If $t \in\left(t_{i}^{n}, t_{i+1}^{n}\right) \cap\left(t_{j}^{m}, t_{j+1}^{m}\right)$, then using the Lipschitzian character of $V$, we have

$$
\begin{aligned}
D^{+} m(t) \leqslant & \limsup _{h \rightarrow 0^{+}} \frac{1}{h}\left[V \left(t+h, x_{n}(t)+h f\left(t, x_{n}(t)\right), x_{m}(t)\right.\right. \\
& \left.\left.\quad+h f\left(t, x_{m}(t)\right)\right)-V\left(t, x_{n}(t), x_{m}(t)\right)\right] \\
& \left.+L\left[\| x_{n}^{\prime}(t)-f\left(t, x_{n}\left(t, x_{n}\right)\right)\right)\|+\| x_{m}^{\prime}(t)-f\left(t, x_{m}(t)\right) \|\right] .
\end{aligned}
$$

Since $\left\|x_{n}(t)-x_{n}\left(t_{i}^{n}\right)\right\| \leqslant M\left(t-t_{i}^{n}\right)$, by (iv) and (v) of Lemma 2.1,

$$
\begin{aligned}
\left\|x_{n}^{\prime}(t)-f\left(t, x_{n}(t)\right)\right\| \leqslant & \left\|x_{n}^{\prime}(t)-f\left(t_{i}^{n}, x_{n}\left(t_{i}^{n}\right)\right)\right\| \\
& +\left\|f\left(t_{i}^{n}, x_{n}\left(t_{i}^{n}\right)\right)-f\left(t, x_{n}(t)\right)\right\| \\
\leqslant & 2 \epsilon_{n} .
\end{aligned}
$$

Similarly $\left\|x_{m}^{\prime}(t)-f\left(t, x_{m}(t)\right)\right\| \leqslant 2 \epsilon_{m}$. Consequently, we get, because of (2.3) and (3.4), the different inequality

$$
D^{+} m(t) \leqslant g(t, m(t))+2 L\left(\epsilon_{n}+\epsilon_{m}\right),
$$

which is true for all but a countable number of $t \in\left[t_{0}, t_{0}+a\right]$. Since $m\left(t_{0}\right)$ $=0$, Theorem 2.1 gives

$$
m(t) \leqslant r_{n, m}\left(t, t_{0}, 0\right), \quad t \in\left[t_{0}, t_{0}+a\right],
$$

where $r_{n, m}\left(t, t_{0}, 0\right)$ is the maximal solution of $u^{\prime}=g(t, u)+2 L\left(\epsilon_{n}+\epsilon_{m}\right)$, $u\left(t_{0}\right)=0$. By Lemma $2.3, \lim _{n, m \rightarrow \infty} r_{n, m}\left(t, t_{0}, 0\right)=r\left(t, t_{0}, 0\right)$ uniformly on $\left[t_{0}, t_{0}+a\right]$, where $r\left(t, t_{0}, 0\right)$ is the maximal solution of (2.2). But by $\left(\mathrm{A}_{3}\right)$, $r\left(t, t_{0}, 0\right) \equiv 0$ on $\left[t_{0}, t_{0}+a\right]$. It therefore follows that

$$
\lim _{n, m \rightarrow \infty} V\left(t, x_{n}(t), x_{m}(t)\right)=0
$$

and consequently by $\left(\mathrm{A}_{4}\right)$, the sequence $\left\{x_{n}(t)\right\}$ is uniformly Cauchy on $\left[t_{0}, t_{0}+a\right]$. Hence problem $(2.1)$ has a solution on $\left[t_{0}, t_{0}+a\right)$.

To prove uniqueness, if $x(t)$ and $y(t)$ are two solutions of (2.1), we let $m(t)=V(t, x(t), y(t))$ to obtain

$$
D^{+} m(t) \leqslant g(t, m(t)), \quad t \in\left[t_{0}, t_{0}+a\right] .
$$

The fact $m\left(t_{0}\right)=0$ implies, by Theorem 2.1 , that $m(t) \leqslant r\left(t, t_{0}, 0\right), t \in$ $\left[t_{0}, t_{0}+a\right]$ where $r\left(t, t_{0}, 0\right)$ is the maximal solution of (2.2) which is identically zero by $\left(\mathrm{A}_{3}\right)$. Thus $m(t) \equiv 0$ on $\left[t_{0}, t_{0}+a\right]$ and this completes the proof of Theorem 3.2 . 
The assumption $F_{0}$ is convex was crucial in the proof of Theorem 3.2. In general, we have to use different approaches.

THEOREM 3.3. Let assumptions $\left(\mathrm{A}_{1}\right)$ to $\left(\mathrm{A}_{4}\right)$ hold except that condition (2.3) in $\left(\mathrm{A}_{4}\right)$ is replaced by

$$
\begin{aligned}
\lim \sup & \frac{1}{h}\left[V\left(t+h, x+h f\left(t, x_{1}\right), y+h f\left(x, y_{1}\right)\right)-V(t, x, y)\right] \\
& \leqslant g(t, V(t, x, y))+P\left(|t-s|+\left\|x-x_{1}\right\|+\left\|y-y_{1}\right\|\right),
\end{aligned}
$$

for $s, t \in\left[t_{0}, t_{0}+a\right], x, y \in F$ and $x_{1}, y_{1} \in F_{0}$, where $p: R^{+} \rightarrow R^{+}$is nondecreasing and $\lim _{u \rightarrow 0} p(u)=0$. Then problem (2.1) has a unique solution on $\left[t_{0}, t_{0}+a\right)$.

Proof. Let $n, m$ be positive integers and let $m(t)=V\left(t, x_{n}(t), x_{m}(t)\right)$, $t \in\left[t_{0}, t_{0}+a\right]$. If $t \in\left(t_{i}^{n}, t_{i+1}^{n}\right) \cap\left(t_{j}^{m}, t_{j+1}^{m}\right)$, using the Lipschitzian character of $V$, Lemma 2.1(iv), and (3.5), we get

$$
\begin{aligned}
& D^{+} m(t) \leqslant \limsup _{h \rightarrow 0^{+}} \frac{1}{h}\left[V \left(t+h, x_{n}(t)+h f\left(t_{i}^{n}, x_{n}\left(t_{i}^{n}\right)\right), x_{m}(t)\right.\right. \\
& \left.\left.\quad+h f\left(t_{j}^{m}, x_{m}\left(t_{j}^{m}\right)\right)-V\left(t, x_{n}(t), x_{m}(t)\right)\right)\right]+L\left(\epsilon_{n}+\epsilon_{m}\right) \\
& \quad \leqslant g(t, m(t))+p\left[\left|t_{i}^{n}-t_{j}^{m}\right|+\left\|x_{n}(t)-x_{n}\left(t_{i}^{n}\right)\right\|+\left\|x_{m}(t)-x_{m}\left(t_{j}^{m}\right)\right\|\right] \\
& \quad+L\left(\epsilon_{n}+\epsilon_{m}\right) .
\end{aligned}
$$

Since $\left|t_{i}^{n}-t_{j}^{m}\right| \leqslant \epsilon_{n}+\epsilon_{m},\left\|x_{n}(t)-x_{n}\left(t_{i}^{n}\right)\right\| \leqslant M \epsilon_{n}$ and $\left\|x_{n}(t)-x_{m}\left(t_{j}^{m}\right)\right\|$ $\leqslant M \epsilon_{m}$, and $p(u)$ is nondecreasing in $u$, we have

$$
D^{+} m(t) \leqslant g(t, m(t))+\beta_{m, n},
$$

where $\beta_{m, n}=p\left[(1+M)\left(\epsilon_{n}+\epsilon_{m}\right)\right]+L\left(\epsilon_{n}+\epsilon_{m}\right)$. Notice that $\lim _{n, m \rightarrow \infty} \beta_{n, m}$ $=0$ in view of the property of $p(u)$, we proceed as in the corresponding part of the proof of Theorem 3.2, to complete the proof as before.

THEOREM 3.4. Let assumptions $\left(\mathrm{A}_{1}\right),\left(\mathrm{A}_{2}\right),\left(\mathrm{A}_{3}\right)$ and $\left(\mathrm{A}_{5}\right)$ hold and let $g(t, u)$ be nondecreasing in $u$ for each $t \in\left[t_{0}, t_{0}+a\right]$. Then problem (2.1) has a unique solution on $\left[t_{0}, t_{0}+a\right]$.

Proof. Let $m, n$ be positive integers and let $m(t)=V\left(y_{n}(t)-y_{m}(t)\right)$ for $t \in\left[t_{0}, t_{0}+a\right]$, where $y_{p}(t)$ are the functions constructed in Lemma 2.4. Using Lemma 2.4(iii) and Lemma 2.5, we have

$$
\begin{aligned}
D_{+} m(t) & \leqslant M\left[y_{n}(t)-y_{m}(t), y_{n}^{\prime}(t)-y_{m}^{\prime}(t)\right] \\
& \leqslant g(t, m(t))+\left(1+N\left\|y_{n}(t)-y_{m}(t)\right\|\right)\left(\epsilon_{n}+\epsilon_{m}\right),
\end{aligned}
$$

for $t \in\left[t_{k}, t_{k+1}\right)$. Also, $\left\|y_{n}(t)-y_{m}(t)\right\| \leqslant 2\left(b+\left\|x_{0}\right\|\right) \equiv L$. Moreover, for each $k \geqslant 1$,

$$
\left|m\left(t_{k}\right)-m\left(t_{\bar{k}}\right)\right| \leqslant L\left[\left\|y_{n}\left(t_{k}\right)-y_{n}\left(t_{\bar{k}}\right)\right\|+\left\|y_{m}\left(t_{k}\right)-y_{m}\left(t_{\bar{k}}\right)\right\|\right] .
$$


Hence, in view of (iv) and (v) of Lemma 2.4, we obtain

$$
\begin{aligned}
\sum_{k=1}^{\infty}\left|m\left(t_{k}\right)-m\left(t_{\bar{k}}\right)\right| & \leqslant 3 L\left[\sum_{i=0}^{\infty}\left(t_{i+1}^{n}-t_{i}^{n}\right) \epsilon_{n}+\sum_{j=0}^{\infty}\left(t_{j+1}^{m}-t_{j}^{m}\right) \epsilon_{m}\right] \\
& \leqslant 3 L a\left(\epsilon_{n}+\epsilon_{m}\right) \equiv \eta_{m, n} .
\end{aligned}
$$

Furthermore, $m\left(t_{0}\right)=0$. An application of Theorem 2.2 yields

$$
m(t) \leqslant r_{m, n}\left(t, t_{0}, \eta_{m, n}\right), \quad t \in\left[t_{0}, t_{0}+a\right],
$$

where $r_{m, n}\left(t, t_{0}, u_{0}\right)$ is the maximal solution of

$$
u^{\prime}=g(t, u)+(L+1)\left(\epsilon_{m}+\epsilon_{n}\right), u\left(t_{0}\right)=\eta_{m, n} .
$$

As before, we can conclude by Lemma $2.1,\left(A_{3}\right)$ and $\left(A_{5}\right)$,

$$
\lim _{n, m \rightarrow \infty}\left\|y_{n}(t)-y_{m}(t)\right\|=0
$$

and this implies by Lemma 2.4(iv) that $\lim _{n, m \rightarrow \infty}\left\|x_{n}(t)-x_{m}(t)\right\|=0$. Hence $\left\{x_{n}(t)\right\}$ is uniformly Cauchy on $\left[t_{0}, t_{0}+a\right]$ and the proof is complete.

REMARKS. In the boundary condition $\left(A_{2}\right)$, "lim" may be replaced by "lim inf". Similarly, in $\left(\mathbf{A}_{4}\right)$, one could employ other generalized derivatives $D^{-} V, D_{-} V$ and $D_{+} V$ in place of $D^{+} V$. The proofs work without any difficulty. However, we need conditions $\left(A_{2}\right)$ and $\left(A_{5}\right)$ as stated, both of which are used in Theorem 3.4.

Consider the special case $V(t, x, y)=\|x-y\|$. Candition (2.3) becomes $\limsup _{h \rightarrow 0^{+}} \frac{1}{h}[\|x-y+h[f(t, x)-f(t, y)]\|-\|x-y\|] \leqslant g(t,\|x-y\|)$, which is clearly satisfied when one assumes Perron's type uniqueness condition (3.1) in Theorem 3.1.

Let $E^{*}$ be the dual space of $E$ and let $J: E \rightarrow 2^{E^{*}}$ be the duality map defined by

$$
J(x)=\left[x^{*} \in E^{*}:\|x *\|=\|x\| \text { and } x *(x)=\|x\|^{2}\right] .
$$

For each $x, y \in E$ define the generalized pairings

$$
(x, y)_{-}=\inf \left[x^{*}(x): x * \in J(y)\right] \text { and }(x, y)_{+}=\sup \left[x^{*}(x): x^{*} \in J(y)\right] \text {. }
$$

If $x, y, z \in E$, we have

$$
(x+y, z)_{ \pm} \leqslant(x, z)_{ \pm}+\|y\|\|z\| .
$$

Also, if $x(t)$ is a differentiable function on $\left[t_{0}, t_{0}+a\right]$ and $m(t)=\|x(t)\|^{2}$, then $D^{-} m(t) \leqslant 2\left(x^{\prime}(t), x(t)\right)_{-}$and $D^{+} m(t) \leqslant 2\left(x^{\prime}(t), x(t)\right)_{+}$. Consequently, the assumptions $(f(t, x)-f(t, y), x-y)_{ \pm} \leqslant L\|x-y\|^{2}$ imply that the choice $V(t, x, y)=\|x-y\| e^{-2 L t}$ is admissible in Theorems 3.2 and 3.3 with $g(t, u) \equiv 0$ 
and $D^{ \pm} V(t, x, y)$. For Theorem 3.4 we take $V(x)=\|x\|^{2}$ and $M[x, y]=(x, y)_{+}$ so that $\left(\mathrm{A}_{5}\right)$ is satisfied since $(x, y)_{+}$is upper semicontinuous. These considerations show that our results contain Theorems 1, 2 and 3 in [4] which in turn include many earlier results.

\section{REFERENCES}

1. V. Lakshmikantham and S. Leela, Differential and integral inequalities. Vols. I, II, Academic Press, New York, 1969.

2. V. Lakshmikantham, Stability and asymptotic behaviour of solutions of differential equations in a Banach space, Lecture notes, CIME, Italy, 1974.

3. - Existence and comparison results for differential equations in a Banach space, (Proc. Internat. Conf. Differential Equations, Univ. of Southern California, Los Angeles, 1974), Academic Press, New York, 1975, pp. 459-473.

4. R. H. Martin, Differential equations on closed subsets of a Banach space, Trans. Amer. Math. Soc. 179 (1973), 399-414. MR 47 \#7537.

5. T. Ważewski, Sur l'existence et l'unicité des intégrales des équations différentielles ordinaires au cas de l'espace de Banach, Bull. Acad. Polon. Sci. Sér. Sci. Math. Astronom. Phys. 8 (1960), 301-305. MR 24 \#A892.

6. G. Ladas and V. Lakshmikantham, Differential equations in abstract spaces, Academic Press, New York, 1972.

DEPARTMENT OF MATHEMATICS, UNIVERSITY OF TEXAS, ARLINGTON, TEXAS 76019 